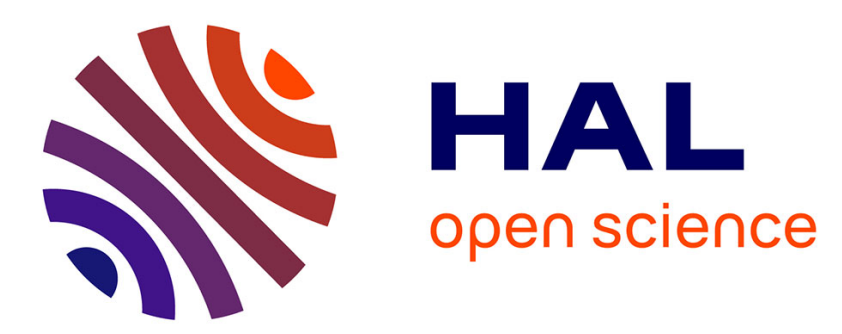

\title{
The contribution of the lesion approach to the neuroscience of creative cognition
}

Marcela Ovando-Tellez, Theophile Bieth, Matthieu Bernard, Emmanuelle

Volle

\section{- To cite this version:}

Marcela Ovando-Tellez, Theophile Bieth, Matthieu Bernard, Emmanuelle Volle. The contribution of the lesion approach to the neuroscience of creative cognition. Current Opinion in Behavioral Sciences, 2019, 27, pp.100-108. 10.1016/j.cobeha.2018.10.011 . hal-02271207

\section{HAL Id: hal-02271207 https: / hal.sorbonne-universite.fr/hal-02271207}

Submitted on 26 Aug 2019

HAL is a multi-disciplinary open access archive for the deposit and dissemination of scientific research documents, whether they are published or not. The documents may come from teaching and research institutions in France or abroad, or from public or private research centers.
L'archive ouverte pluridisciplinaire HAL, est destinée au dépôt et à la diffusion de documents scientifiques de niveau recherche, publiés ou non, émanant des établissements d'enseignement et de recherche français ou étrangers, des laboratoires publics ou privés. 


\section{The contribution of the lesion approach to the neuroscience of creative cognition Marcela P Ovando-Tellez ${ }^{1}$, Theophile Bieth ${ }^{1}$, Matthieu Bernard and Emmanuelle Volle}

\begin{abstract}
Psychological and recent neuroimaging findings indicate that creativity relies on a balance between associative thinking likely supported by the default mode network and cognitive control processes sustained by control-related networks including frontoparietal regions. Exploring patients with brain lesions allows testing this model and ascertaining a more causal link between creative processes and brain systems. Results from the lesion approach provide arguments for the critical role of the default mode network and the frontoparietal control network for associative and controlled processes, respectively, and identify critical nodes within these networks. The few lesion studies that have been performed also suggest a functional specialization of several prefrontal regions for distinct creative processes. In the current review, we integrate the results of lesion studies with the findings emerging from both recent functional imaging and non-invasive brain stimulation studies, in an attempt to better understand the cognitive and brain mechanisms of creativity or the potential ways to improve this knowledge.
\end{abstract}

\section{Address}

FRONTLAB, Institut du cerveau et la moelle (ICM) - Sorbonne Université, INSERM, CNRS Hôpital Pitié Salpêtrière, 47, bd de l'hôpital, F-75013, Paris, France

Corresponding author: Volle, Emmanuelle (emmavolle@gmail.com) ${ }^{1}$ These authors equally contributed to the review.

\section{Introduction}

A creative production can be viewed both as the result of high-level control functions or top-down processes (including inhibitory control) and as the result of a relaxation of one's constraints or inhibitions, possibly favoring spontaneous associative thinking and bottom-up processes. These two views make opposite predictions regarding the role of the prefrontal cortex (PFC), that support controlled functions, in creativity. Recent cognitive models try to conciliate these views and consider spontaneous associative and controlled processes as complementary rather than paradoxical in the creative process [1-5]. With the development of network neuroscience based on functional connectivity, the neuroimaging of creative cognition in healthy subjects have started to clarify the multiple brain systems involved in associative and controlled creative processes, and to specify the place of the PFC in these systems. The lesion approach may be especially useful in complementing functional imaging toward a better understanding of the cerebral substrate of creativity, by identifying critical nodes in the diversity of brain networks reported in functional imaging, and precising their specific role in the creativity processes [6]. Surprisingly, very few lesion studies have investigated creative abilities in brain damaged patients $\left[7-14,15^{\bullet}, 16,17,18^{\bullet}\right.$ ] ('Table 1). Focusing on the neuroscientific literature of creativity, especially coming from patients, this review will explore not only whether the PFG is critical for creative abilities, but more importantly what prefrontal systems are necessary for associative or controlled creative processes.

\section{Recent cognitive and neuroimaging findings}

The cognitive neuroscience of creativity provides abundant experimental evidence of the important role of PFCdependent cognitive control functions in creative abilities. These functions include inhibition of prepotent responses [19-21], controlled retrieval [22-24] and working memory [25,26]. Neuroimaging data using taskrelated activation and functional connectivity in healthy subjects are consistent with this view. Several metaanalyses of creativity-related activation studies have reliably shown that lateral frontal and parietal areas are the most recruited set of regions in creativity tasks [27-29]. Functional connectivity analyses have highlighted the importance of the control-related networks including the frontoparietal network in creativity [30,31 $\left.{ }^{\bullet \bullet}\right]$. The lateral PFC region may be especially recruited for inhibition of dominant responses [20], controlled retrieval $[23,24]$, and selection or evaluation processes [32].

Aside from the deliberate control processes, creative thinking also involves more spontaneous associative processes. The role of associative thinking abilities in creativity may rely on the organization of associations between elements of one's semantic knowledge that determines the ability to generate and combine remote 


\begin{tabular}{|c|c|c|c|c|}
\hline \multicolumn{5}{|c|}{$\begin{array}{l}\text { Patient group studies on creative cognition in adults. The table includes studies in patients that related creative abilities to an anatomical location of a lesion or neurodegenerative } \\
\text { impairment. Case reports already described in a previous review [60] are not included }\end{array}$} \\
\hline Study & Task & Region & Network & Effect \\
\hline \multicolumn{5}{|c|}{ Group studies of focal lesions } \\
\hline \multirow{2}{*}{ Reverberi et al. $[7]^{\text {a }}$} & Match stick problem-solving & Lateral PFC versus controls & N.A. & $\uparrow$ correct responses (type C) \\
\hline & & 'Pure' medial PFC versus controls and versus lateral PFC & N.A. & $\downarrow$ correct responses (type A) \\
\hline \multirow{5}{*}{ Shamay-Tsoory et al. [10] ${ }^{b}$} & TTCT and AUT & mPFC versus controls and versus parietotemporal patients & N.A. & $\downarrow$ total score \& originality \\
\hline & & $\begin{array}{l}\text { mPFC+IFG versus controls and versus parietotemporal } \\
\text { patients }\end{array}$ & N.A. & $\downarrow$ total score \& originality \\
\hline & & Right mPFC region & N.A. & $\downarrow$ originality with $\uparrow$ lesion size \\
\hline & & Left parietotemporal patients & N.A. & $\uparrow$ originality with $\uparrow$ lesion size \\
\hline & & $\begin{array}{l}\text { Identified a subgroup of patients with mainly left } \\
\text { parietotemporal or IFG lesions with higher originality index }\end{array}$ & N.A. & $\uparrow$ originality \\
\hline \multirow[t]{6}{*}{ Abraham et al. [11] ${ }^{\mathrm{c}}$} & AUT & Lateral PFC versus controls & N.A. & $\downarrow$ originality, fluency \\
\hline & Imagery task & Lateral PFC versus controls & N.A. & $\downarrow$ practicality \\
\hline & Imagery task & Temporoparietal patients versus controls & N.A. & $\downarrow$ practicality \\
\hline & CET & Temporoparietal patients versus controls & N.A. & More constrained \\
\hline & Concept expansion & Tested but no significant lesion location & N.A. & \\
\hline & RAT & Tested but no significant lesion location & N.A. & \\
\hline Duff et al. [12] & ТТСТ & Hippocampal damage versus controls & N.A. & $\downarrow$ originality, fluency, flexibility \& elaboration \\
\hline Ghacibeh et al. [13] & ТTCT & Left versus right anterior temporal lobectomy & N.A. & $\begin{array}{l}\text { No difference between left \& right } \\
\text { lobectomy (no control group) }\end{array}$ \\
\hline Warren et al. [15] & RAT & Hippocampal damage versus controls & N.A. & $\downarrow$ correct responses \\
\hline \multicolumn{5}{|c|}{ VSLM and disconnection-deficit mapping on focal lesions } \\
\hline \multirow[t]{2}{*}{ Bendetowicz et al. [17] } & RAT-like & Left rostrolateral PFC, FMT, ATR, FSP & Left FPCN & $\downarrow$ remote associates combination \\
\hline & Word-association task & Right rostromedial PFC, Cingulate tract & $\mathrm{DMN}$ & $\downarrow$ remote word associations \\
\hline \multicolumn{5}{|c|}{ Group studies on neurodegenerative diseases } \\
\hline \multirow[t]{2}{*}{ Rankin et al. [8] d } & Figural TTCT & FTD versus controls & N.A. & $\downarrow$ resistance to premature closure \\
\hline & & $\mathrm{SD}$ versus controls & N.A. & $\begin{array}{l}\downarrow \text { fluency, originality, elaboration \& } \\
\text { resistance to premature closure }\end{array}$ \\
\hline \multirow{3}{*}{ De Souza et al. [9] } & TTCT & FTD versus controls & N.A. & $\downarrow$ originality, fluency, flexibility \\
\hline & & FTD versus Parkinson patients & N.A. & $\downarrow$ originality, fluency, flexibility \\
\hline & & $\begin{array}{l}\text { VBM-like analysis on SPECT data identified the rostral PFC, } \\
\text { posterior parietal and laterotemporal regions }\end{array}$ & N.A. & $\begin{array}{l}\text { Integrity of these regions correlated with } \\
\text { TTCT scores }\end{array}$ \\
\hline Canesi et al. [16] & ATTA & $\begin{array}{l}\text { PSP versus controls, versus Parkinson patients and versus } \\
\text { MSA patients }\end{array}$ & N.A. & $\downarrow$ originality, fluency, flexibility, elaboration \\
\hline \multicolumn{5}{|c|}{ 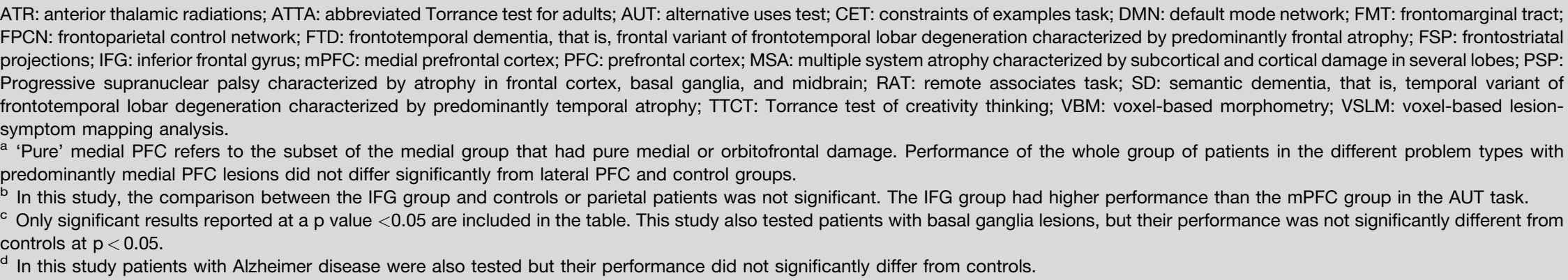 } \\
\hline
\end{tabular}


associations [33]. In support of this theory, psychological studies have shown that more creative people have more flexible semantic associations, allowing them to connect more distant concepts or words $\left[34-36,37^{\bullet}, 38^{\bullet \bullet}, 39,40^{\bullet}\right]$. Although the cerebral substrates of associative processing are not elucidated, recent evidence supports the role of the default mode network (DMN) in unconstrained associative thinking $\left[40^{\circ}\right]$ and more broadly in spontaneous cognition [41] including mind wandering [42,43] and contextual associations [44]. Several studies have shown that the morphometry and functional connectivity of DMN regions correlate with creative performance [4551]. Consistent with the role of semantic associations in creativity, semantic memory regions are also important for creative abilities $[11,27,28]$ and have both overlaps and functional interactions with the DMN that remain to be clarified [20,52,53].

Overall, the cognitive neuroscience of creativity now considers that creative abilities result from an interaction or a balance between associative and controlled processes [1-5]. Recent functional connectivity studies strongly support this view by demonstrating that two main networks interact during creativity tasks: a lateral frontoparietal control network (FPCN), known to support control functions, and the DMN, that has been related to associative thinking and spontaneous cognition $\left[31^{\bullet \bullet}, 32,54,55^{\bullet}\right]$. The interaction between these systems might be mediated by the Salience network [30] or by regions of these networks acting as connector hubs. The identification of large scale networks that involve different parts of the PFG is an important step in understanding the cerebral basis for creativity and offers new predictions regarding which creativity mechanisms can be impacted by specific lesion locations.

\section{Critical role of the DMN and FPCN for creativity (Table 1)}

To explore whether the DMN and FPGN are critical for creative processes, Bendetowicz et al. [17] performed a lesion study on patients with single focal frontal lesions. To assess creative abilities, the authors used the Combined Association Task, an adaptation of Mednick's Remote Associates Task (RAT), in which three unrelated cue words are presented, and the subject has to provide a solution word related to all three cue words. Because Mednick's theory predicts that associative processes are required during RAT-like tasks, the same patients performed a simple word-to-word association task. In this task, patients were instructed to provide the first word that came to mind in response to a given cue word and an unusual associate of the same cue word. The results showed that damage to the left FPCN impaired the performance on the RAT-like task, while damage to the DMN impaired the ability to generate unusual word associations. Hence, these results confirm recent functional connectivity findings $\left[30,31^{\bullet \bullet}\right]$ by showing the crucial role of both DMN and FPCN in creativity.

The critical role of the DMN in creativity is consistent with previous lesion studies that showed a deficit in both RAT $\left[15^{\circ}\right]$ and divergent thinking [12] tasks in patients with damage to the hippocampus, a DMN-related region. A rostromedial PFC damage, another region that is thought to belong to the DMN, has been associated with a divergent thinking impairment in Shamay-Tsoory et al.' s study [10], which highlighted difficulties in generating original ideas in these patients. However, this result was not replicated by Abraham et al., who did not observe significant deficits in divergent thinking in polar and/or orbitofrontal patients [11]. A medial PFC lesion also appears to impact mind wandering [56], a mental activity shown to be related to creativity abilities. In line with lesion studies, direct brain stimulation studies using transcranial direct-current stimulation (tDCS) have shown that stimulating the medial PFC could improve the remoteness of word associations during a word-generation task in certain conditions $[57,58]$, and inhibiting this region could also decrease mind wandering [59]. According to Bendetowicz et al. [17], the DMN, and especially its medial PFG regions, may be critical for a particular thinking type or mode characterized by a spontaneous and associative spread of thoughts that is essential in RAT-like tasks. Voxel-based lesion deficit mapping analyses revealed that when a lesion affected the rostromedial prefrontal region, patients produced more common or typical word associates, with or without the instruction to think unusually, which is consistent with a 'rigidity' in semantic associations, and may explain that these patients also had poor creativity performance. The 'rigidity' of semantic associations that may results from a DMN lesion impacts the generation of unusual associations, which impairs remote thinking in both convergent and divergent tasks. This interpretation supports Mednick's hypothesis, only tested previously in healthy subjects. The organization of semantic associations also likely relates to semantic memory that has been shown critical for divergent thinking [8; but see Ref. 13]. However, the relationships between the DMN and semantic memory network for associative thinking remains to be clarified.

The critical role of the FPGN has been shown in several patient studies. In patients with a frontal neurodegenerative disease, De Souza et al. [9] showed that divergent thinking scores correlated with atrophy in prefrontal, temporal, and parietal regions that overlap with the FPCN. Rankin et al. [8, see also Ref. 16] reported that both frontal and temporal neurodegenerative diseases affected divergent thinking. In patients with focal lesions, a left rostrolateral PFC lesion has been associated with decreased performance on RAT-like tasks [17]. More caudal lateral PFG lesions as explored by Abraham 
et al. [11] were associated with decreased fluency and originality of ideas produced in divergent thinking tasks and temporoparietal lesions with an increased fixation on examples. Both lateral frontal and temporoparietal lesions impacted divergent thinking tasks and a creative imagery task [11]. These data suggest that several regions of the FPCN are essential to various creativity tasks. On the contrary, other findings suggested an increased originality of ideas after a left posterior parietotemporal lesion, and possibly a left inferior frontal lesion [10, see also Ref. 14], and better problem solving abilities after a lateral PFC lesion [7]. A few patient reports have described the emergence or improvement of creative artistic abilities after a frontotemporal disease ([60,61] for reviews). Hence, patient studies provide inconsistent conclusions regarding the critical role of frontoparietal regions in creativity. Similarly, non-invasive brain stimulation studies targeting the left lateral prefrontal cortex have shown divergent effects on creative performance: both cathodal $\left[62,63^{\circ}, 64^{\circ}\right]$ and anodal [65-68] tDCS of the left lateral PFC, aiming to suppress or elicit the activity of this region respectively, have been reported to increase creative abilities. Overall, the few lesion and brain stimulation studies that have been conducted confirm the importance of FPCN regions for creativity, but some of them challenge the role of the left lateral PFC. This discrepancy may be explained by the combination of: firstly, a lack of precision regarding the exact location of lesions/stimulation and the networks impacted by them, secondly, a functional heterogeneity of prefrontal regions regarding creativity processes and thirdly, differences in the processes most required by the creativity tasks that have been used.

\section{Specialization of the lateral PFC for distinct creative mechanisms (Figure 2)}

The PFC appears to be the most consistently explored and/or reported region in lesion (and brain stimulation) studies, which may allow to examine whether a functional PFG organization for creativity can emerge. It is likely that patient and brain stimulation studies lack anatomical precision and target distinct areas of the PFC within or outside the FPCN. Except for Bendetowicz et al. [17], lesion studies on creativity did not use voxel-based methods to specify the location of the critical area and did not analyze which networks were affected by the lesion. By using these approaches $\left[69^{\circ}\right]$, Bendetowicz et al. [17] were able to identify a specific area that was critical for verbal creativity, and clarified to which networks it was connected. In the left FPCN, the rostrolateral PFC region and its connections were critical for solving RAT-like problems (Figure 1). Yet, patients with a lesion in this region did not have any difficulties generating close or remote word associates, indicating that the left rostrolateral PFC plays a critical role in RAT-like tasks by affecting control rather than associative processes. The pivotal role of the rostrolateral PFC in
Figure 1

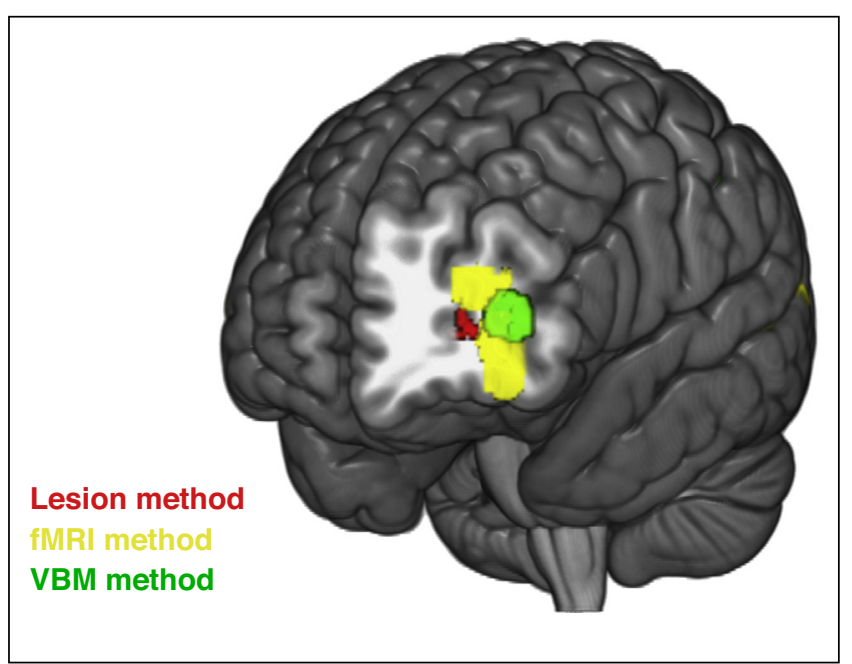

Converging results on the role of the left rostrolateral PFC in creativity. On a brain surface rendering is displayed the overlap of the critical lesion location for RAT-like performance in patients (red; [17]), a morphometry map of brain regions which structure correlated with RAT-like performance in healthy subjects (green; [70]) and results from a meta-analysis of functional imaging study showing the regions that were more recruited in combination tasks relative to free generation tasks (yellow; [27]).

RAT-like tasks parallels morphometry findings in healthy subjects, showing that the volume of the left rostrolateral PFC was associated with better performance in such task [70]. In addition, a meta-analysis of functional MRI studies showed that tasks involving the combination of remote elements activated the left rostrolateral PFC more than other creativity tasks [27]. Combined with the established of the left rostrolateral PFC in relational integration and multitasking, and consistent with the link between the RAT and relational reasoning $\left[71-74,75^{\circ}\right]$, these data suggest that the role of this region is to integrate the relationships between several pairs of words during RAT trials, possibly by coordinating or branching the associative and controlled processing.

In posterior areas, a functional specialization of distinct prefrontal subregions or FPCN subregions for creativity processes has been proposed [24] (Figure 2). For instance, ventral and dorsal prefrontal regions are proposed to play a role in the generative versus evaluative steps of the creative process, respectively. Although functional imaging studies have highlighted the key role of the left inferior frontal gyrus in creativity $\left[20,23,27,40^{\circ}, 76,77^{\circ}\right]$, several studies suggested that idea generation may improve when suppressing its activity. Brain stimulation studies that targeted the left inferior frontal gyrus showed that inhibiting this region improved idea generation in a divergent thinking task $\left[62,64^{\circ}, 78,79^{\circ}\right]$, especially if it was 


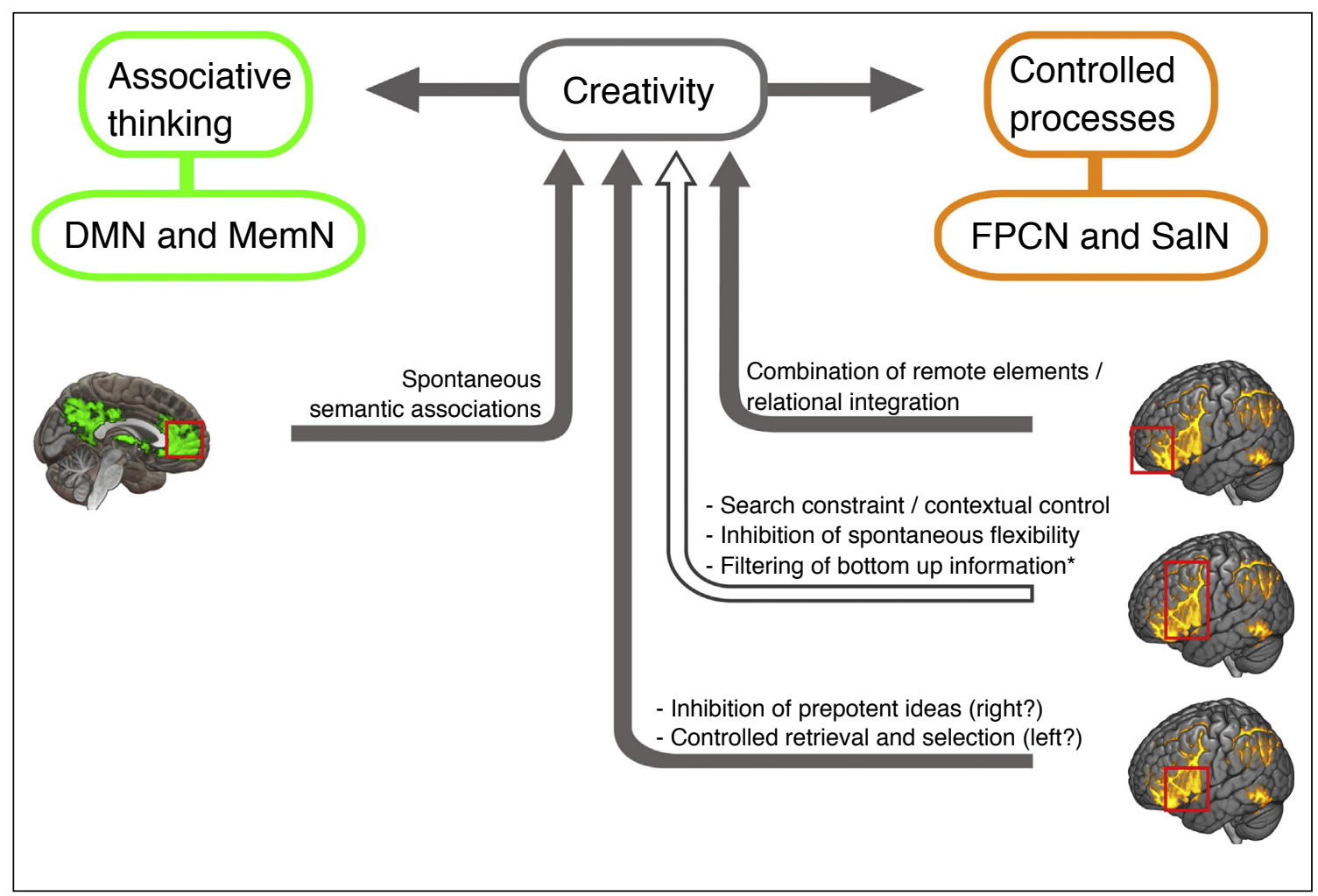

Tentative summary of the findings of lesion studies. The schema represents the reported effect of brain lesions, which decreased (plain arrows) or increased (empty arrow) creative performance, and proposes hypothetical processes that, when affected, can explain these effects. Please note that this schema is necessarily simplistic and does not depict all possible mechanisms and network damages by which brain lesions could theoretically impact creativity. * the exact location of lateral prefrontal lesions (ventral and/or dorsal) and network disruption (FPCN, salience or attentional networks) that may favor creative performance are unclear. DMN: default mode network; FPCN: frontoparietal control network; MemN: semantic and episodic memory networks; SalN: salience network.

combined with a right inferior frontal stimulation, and suggested that the activity of the ventrolateral PFC is deleterious to the idea generation step. One hypothesis that has been put forward is that some of the controlled processes supported by the PFCN are impaired after a left ventrolateral PFC damage, releasing spontaneous associative processing and spontaneous flexibility. Relaxing the control on associative thinking may benefit the generation of original ideas in some tasks and conditions $[67,68]$. However, this explanation questions the nature of the interaction between left inferior frontal gyrus and DMN which functional connectivity has been demonstrated to increase during idea generation and to correlate with creative abilities $\left[31^{\bullet \bullet}, 76,77^{\circ}\right]$. Alternatively, decreasing left lateral prefrontal activity may unfilter and increase the availability of bottom-up perceptual information processed in posterior occipitotemporal regions, which might be explained by the participation of lateral PFG subregions in other networks including the attentional networks $[2,54,62]$. Another hypothesis that has been proposed to explain the improvement of certain problem solving abilities after damage [7] or brain inhibitory stimulation $\left[63^{\circ}\right]$ of the left lateral PFC is that this region plays a role in sculpting the response space in a given situation, resulting in constraining the field of ideas directly available. Altering the function of the lateral PFC may release this constraining role of the context.

Although a constraining role of the left inferior frontal gyrus may be consistent with its critical role in contextual control [80], its negative influence on idea generation may seem to contradict a series of studies that have demonstrated the role of this region in the controlled retrieval of memory [23,53,81-83]. Specifically, patients with left inferior frontal lesion were shown to be impaired in retrieving distant word associates, suggesting an impairment in generating unusual associations or ideas [84]. The potential limiting role of the lateral PFC in idea generation and originality also remains difficult to reconcile with patient studies that showed the crucial role of the inferior PFC in inhibition of dominant responses [85-87]. To date, two main hypotheses of prefrontal organisation have been proposed to reconcile the 
beneficial and deleterious effects of caudal prefrontal lesions/brain stimulation on creativity. The first one considers that ventral and dorsal caudal PFC regions have opposite roles in the generative and evaluative steps of divergent thinking. The activity of the ventrolateral PFC may be deleterious to the generation step that requires less control processes $\left[32,64^{\circ}\right]$, while other prefrontal regions are important for the more controlled evaluation step [67] or for the inhibition of constraints [20]. The second one is to consider a balance between left and right ventrolateral PFC rather than the role of each region separately [78]. For instance, the left and right ventrolateral PFG may have specific roles, in constraining the search according to the context and inhibiting the inappropriate or less interesting responses, respectively. Overall, the specialization of the caudal PFC for creativity processes according to an inferiorsuperior or a left-right axis remains to be tested (Figure 2).

Finally, a potential factor influencing the reported results is that different creativity tasks require a different balance between associative and controlled processes, so that altering controlled processes may or may not impact a given task [67]. Existing tDCS studies may support this explanation. In fact, to our knowledge, all tDCS studies targeting the left lateral PFC with anodal stimulation showed improved performance in RAT tasks $[65,88,89]$. All tDCS studies targeting the same region with cathodal stimulation showed an improvement of divergent thinking tasks $\left[62,64^{\circ}, 78,79^{\circ}\right]$. Only one study showed an improvement of divergent thinking after anodal stimulation of the left dorsolateral PFC, but it was conditioned by a priming instruction to think divergently [66], which may have involved more controlled processes than divergent thinking tasks usually require. These data suggest that originality in divergent thinking tasks may depend more on spontaneous associations computed by the DMN while RATlike tasks additionally require the lateral PFC, likely for controlled processes. Problem solving tasks vary according to control demands $\left[63^{\circ}\right]$. The reliance on controlled processes to solve the different creativity task may shape the performance observed after a prefrontal lesion.

Hence, the specific role of distinct prefrontal subregions in creativity processes remains to be clarified and integrated with findings from other fields of cognitive neurosciences. Although the lesion approach may be especially useful to address this question, the conclusions that can be drawn from existing patient studies are limited by the fact that they rarely considered the functional and connective properties of the damaged areas and explored a relatively small number of patients. Precisely defining the lesion location anatomically is thus essential in future studies as close regions in frontal, temporal and parietal lobes are functionally heretogeneous and may belong to distinct networks, including the FPCN, DMN but also salience and attentional networks [90]. The use of voxel-based lesion methods with larger sample size could improve the anatomical resolution of brain-behavior correlations, and is more comparable to functional imaging findings. In addition, connectivity approaches in patients are needed to identify the networks that are anatomically and functionally impacted by the lesion [69 ${ }^{\circ}$ ] (or the brain intervention [91]). New anatomical and functional connectivity methods integrating network-based and lesion approaches in patients are promising avenues for future research on creativity [92]. Such approaches may help to clarify how distinct networks and their interactions support distinct creativity mechanisms, to identify the critical hubs allowing these interactions, and, for instance, to disentangle the role of default mode, semantic, attention, and control networks in creativity.

\section{Conclusions}

Patient studies can provide important information to the neuroscience of creativity by identifying the critical networks and pivotal nodes within the networks. The few lesion studies that have been performed confirmed that the integrity of both the DMN and the left FPCN is important for creative performance. In agreement with predictions from functional imaging in healthy subjects, the DMN appears critical for associative processing and the FPCN for controlled processes. Brain lesions affecting some regions of the left control-related network may imbalance the associative and controlled processes involved in creative thinking, affecting creative performance differently depending on which process is the most required by the task. The lesion approach also helps to clarify the functional organization of the PFG for distinct creative processes, showing a medial-lateral dissociation in rostral PFC for associative versus controlled processes, and suggesting a rostrocaudal lateral specialization for distinct controlled processes.

The contribution of lesion studies to the neuroscience of creativity could be enhanced in the future by combining different measures of creativity with anatomical and functional connectivity methods to identify the networks impacted by the lesion.

\section{Conflict of interest statement}

Nothing declared.

\section{Acknowledgements}

Emmanuelle Volle is supported by FRM grant DEQ20150331725 and program 'Investissements d'avenir' ANR-10-IAIHU-06. Marcela Ovando Tellez is supported by a CONICYT funding. Theophile Bieth was supported by a funding from 'Journées de neurologie de langue française'.

\section{References and recommended reading}

Papers of particular interest, published within the period of review, have been highlighted as:

- of special interest

$\bullet$ of outstanding interest

1. Beaty RE, Silvia PJ, Nusbaum EC, Jauk E, Benedek M: The roles of associative and executive processes in creative cognition. Mem Cognit 2014, 42:1186-1197. 
2. Chrysikou EG, Weber MJ, Thompson-Schill SL: A matched filter hypothesis for cognitive control. Neuropsychologia 2014, 62:341-355.

3. Jung RE: Evolution, creativity, intelligence, and madness: "here be dragons". Front Psychol 2014, 5.

4. Volle E: Associative and controlled cognition in divergent thinking: theoretical, experimental, neuroimaging evidence, and new directions. In The Cambridge Handbook of the Neuroscience of Creativity. Edited by Jung RE, Vartanian O. 2017.

5. Benedek M, Jauk E: Spontaneous and controlled processes in creative cognition. Oxf Handb Spontaneous Thought. 2018 http://dx.doi.org/10.1093/oxfordhb/9780190464745.013.22.

6. Volle E, Levy R, Burgess PW: A new era for lesion-behavior mapping of prefrontal functions. In Principles of Frontal Lobe Function. Edited by Stuss DT, Knight RT. USA: Oxford University Press; 2013:500-523.

7. Reverberi C, Toraldo A, D'Agostini S, Skrap M: Better without (lateral) frontal cortex? Insight problems solved by frontal patients. Brain 2005, 128:2882-2890.

8. Rankin KP, Liu AA, Howard S, Slama H, Hou CE, Shuster K, Miller BL: A case-controlled study of altered visual art production in Alzheimer's and FTLD. Cogn Behav Neurol 2007, 20:48-61.

9. de Souza LC, Volle E, Bertoux M, Czernecki V, Funkiewiez A, Allali G, Leroy B, Sarazin M, Habert M-O, Dubois B et al.: Poor creativity in frontotemporal dementia: a window into the neural bases of the creative mind. Neuropsychologia 2010, 48:3733-3742.

10. Shamay-Tsoory SG, Adler N, Aharon-Peretz J, Perry D, Mayseless N: The origins of originality: the neural bases of creative thinking and originality. Neuropsychologia 2011, 49:178-185.

11. Abraham A, Beudt S, Ott DVM, Yves von Cramon D: Creative cognition and the brain: dissociations between frontal, parietal-temporal and basal ganglia groups. Brain Res 2012, 1482:55-70.

12. Duff MC, Kurczek J, Rubin R, Cohen NJ, Tranel D: Hippocampa amnesia disrupts creative thinking: creative thinking and the hippocampus. Hippocampus 2013, 23:1143-1149.

13. Ghacibeh GA, Heilman KM: Creative innovation with temporal lobe epilepsy and lobectomy. J Neurol Sci 2013, 324:45-48.

14. Mayseless N, Aharon-Peretz J, Shamay-Tsoory S: Unleashing creativity: the role of left temporoparietal regions in evaluating and inhibiting the generation of creative ideas. Neuropsychologia 2014, 64:157-168.

15. Warren DE, Kurczek J, Duff MC: What relates newspaper, - definite, and clothing? An article describing deficits in convergent problem solving and creativity following hippocampal damage: hippocampal damage impairs convergent problem solving. Hippocampus 2016, 26:835-840.

This lesion study provides the first evidence of the critical role of the hippocampus in creative problem solving using the remote associates task in patients with medial temporal lobe damage.

16. Canesi M, Rusconi ML, Cereda E, Ranghetti A, Cereda V, Moroni F, Pezzoli G: Divergent thinking in Parkinsonism: a case-contro study. Front Neurol 2017, 8.

17. Bendetowicz D, Urbanski M, Garcin B, Foulon C, Levy R, Bréchemier M-L, Rosso C, Thiebaut de Schotten M, Volle E: Two critical brain networks for generation and combination of remote associations. Brain 2018, 141:217-233.

18. Rigon A, Reber J, Patel NN, Duff MC: Convergent thinking and - traumatic brain injury: an investigation of performance on the remote associate test. Brain Inj 2018, 32:1110-1114.

This study indicates that moderate to severe traumatic brain injury has an impact on convergent problem solving assessed using the remote associate task.

19. Edl S, Benedek M, Papousek I, Weiss EM, Fink A: Creativity and the Stroop interference effect. Personal Individ Differ 2014 69:38-42.
20. Beaty RE, Christensen AP, Benedek M, Silvia PJ, Schacter DL: Creative constraints: brain activity and network dynamics underlying semantic interference during idea production. Neurolmage 2017, 148:189-196.

21. Camarda A, Borst G, Agogué M, Habib M, Weil B, Houdé O, Cassotti M: Do we need inhibitory control to be creative? Evidence from a dual-task paradigm. Psychol Aesthet Creat Arts 2018, 12:351-358.

22. Benedek M, Jauk E, Fink A, Koschutnig K, Reishofer G, Ebner F, Neubauer AC: To create or to recall? Neural mechanisms underlying the generation of creative new ideas. Neurolmage 2014, 88:125-133.

23. Madore KP, Thakral PP, Beaty RE, Addis DR, Schacter DL: Neura Mechanisms of episodic retrieval support divergent creative thinking. Cereb Cortex 2017:1-17 http://dx.doi.org/10.1093/ cercor/bhx312.

24. Benedek M: The neuroscience of creative idea generation. In Exploring Transdisciplinarity in Art and Sciences. Edited by Kapoula Z, Volle E, Renoult J, Andreatta M. Springer International Publishing; 2018:31-48.

25. Vartanian O, Jobidon M-E, Bouak F, Nakashima A, Smith I, Lam Q, Cheung B: Working memory training is associated with lower prefrontal cortex activation in a divergent thinking task. Neuroscience 2013, 236:186-194.

26. Lee CS, Therriault DJ: The cognitive underpinnings of creative thought: a latent variable analysis exploring the roles of intelligence and working memory in three creative thinking processes. Intelligence 2013, 41:306-320.

27. Gonen-Yaacovi G, de Souza LC, Levy R, Urbanski M, Josse G, Volle E: Rostral and caudal prefrontal contribution to creativity: a meta-analysis of functional imaging data. Front Hum Neurosc 2013, 7:465

28. Boccia M, Piccardi L, Palermo L, Nori R, Palmiero M: Where do bright ideas occur in our brain? Meta-analytic evidence from neuroimaging studies of domain-specific creativity. Front Psychol 2015, 6.

29. Wu X, Yang W, Tong D, Sun J, Chen Q, Wei D, Zhang Q, Zhang M Qiu J: A meta-analysis of neuroimaging studies on divergent thinking using activation likelihood estimation. Hum Brain Mapp 2015, 36:2703-2718.

30. Beaty RE, Benedek M, Silvia PJ, Schacter DL: Creative cognition and brain network dynamics. Trends Cogn Sci 2016, 20:87-95.

31. Beaty RE, Kenett YN, Christensen AP, Rosenberg MD,

-• Benedek M, Chen Q, Fink A, Qiu J, Kwapil TR, Kane MJ et al. Robust prediction of individual creative ability from brain functional connectivity. Proc Natl Acad Sci U S A 2018, 115:1087-1092.

The authors used connectome-based predictive modeling based on MR functional connectivity and show that creative abilities can be predicted by the strength of the interaction between regions from the default mode, salience, and executive control networks.

32. Ellamil M, Dobson C, Beeman M, Christoff K: Evaluative and generative modes of thought during the creative process. Neurolmage 2012, 59:1783-1794

33. Mednick SA: The associative basis of the creative process. Psychol Rev 1962, 69:220-232.

34. Groborz M, Necka E: Creativity and cognitive control: explorations of generation and evaluation skills. Creat Res $J$ 2003, 15:183-197.

35. Kenett YN, Anaki D, Faust M: Investigating the structure of semantic networks in low and high creative persons. Front Hum Neurosci 2014, 8.

36. Rossmann E, Fink A: Do creative people use shorter associative pathways? Personal Individ Differ 2010, 49:891-895.

37. Benedek M, Kenett YN, Umdasch C: How semantic memory

- structure and intelligence contribute to creative thought: network science approach. Think Reason 2017, 23:158-183. 
The authors developed a new relatedness judgment task to build individual semantic networks. The results show that the properties of semantic networks correlate with creativity measures.

38. Kenett YN, Levy O, Kenett DY, Stanley HE, Faust M, Havlin S:

- Flexibility of thought in high creative individuals represented by percolation analysis. Proc Natl Acad Sci U S A 2018, 115:867872.

This study quantified the flexibility of thought in high and low creative people by assessing the effect of removing specific links in semantic networks. This percolation analysis showed that creative abilities were related to the flexibility or robustness of the networks. The robustness to network percolation could be explained by the structure of the networks, especially by stronger links between network components in creative people's graphs.

39. Kenett YN: Investigating creativity from a semantic network perspective. In Exploring Transdisciplinarity in Art and Sciences. Edited by Kapoula Z, Volle E, Renoult J, Andreatta M. Springer International Publishing; 2018:49-75.

40. Marron TR, Lerner Y, Berant E, Kinreich S, Shapira-Lichter I,

- Hendler T, Faust M: Chain free association, creativity, and the default mode network. Neuropsychologia 2018, 118(Pt. A):40-58 http://dx.doi.org/10.1016/j.neuropsychologia.2018.03.018.

This fMRI study explored the brain correlates of associative thinking using a chain associative fluency task. The results showed that associative fluency recruited the default mode network together with lateral prefrontal and temporolateral regions and suggested that the unconstrained and spontaneous nature of an associative fluency task might be related to DMN activity, while more controlled processes of fluency task rely on prefrontal regions.

41. Andrews-Hanna JR, Reidler JS, Huang C, Buckner RL: Evidence for the default network's role in spontaneous cognition. $J$ Neurophysiol 2010, 104:322-335.

42. Fox KCR, Spreng RN, Ellamil M, Andrews-Hanna JR, Christoff K: The wandering brain: meta-analysis of functional neuroimaging studies of mind-wandering and related spontaneous thought processes. Neurolmage 2015, 111:611621.

43. Christoff K, Irving ZC, Fox KCR, Spreng RN, Andrews-Hanna JR Mind-wandering as spontaneous thought: a dynamic framework. Nat Rev Neurosci 2016, 17:718.

44. Bar M, Aminoff E, Mason M, Fenske M: The units of thought. Hippocampus 2007, 17:420-428.

45. Takeuchi H, Taki Y, Hashizume H, Sassa Y, Nagase T, Nouchi R, Kawashima R: The association between resting functional connectivity and creativity. Cereb Cortex 2012, 22:2921-2929.

46. Jung RE: The structure of creative cognition in the human brain. Front Hum Neurosci 2013, 7.

47. Fink A, Koschutnig K, Hutterer L, Steiner E, Benedek M, Weber B, Reishofer G, Papousek I, Weiss EM: Gray matter density in relation to different facets of verbal creativity. Brain Struct Funct 2014, 219:1263-1269.

48. Kühn S, Ritter SM, Müller BCN, van Baaren RB, Brass M, Dijksterhuis A: The importance of the default mode network in creativity-a structural MRI study. J Creat Behav 2014, 48:152163.

49. Chen Q-L, Xu T, Yang W-J, Li Y-D, Sun J-Z, Wang K-C, Beaty RE, Zhang Q-L, Zuo X-N, Qu J: Individual differences in verbal creative thinking are reflected in the precuneus. Neuropsychologia 2015, 75:441-449.

50. Jauk E, Neubauer AC, Dunst B, Fink A, Benedek M: Gray matter correlates of creative potential: a latent variable voxel-based morphometry study. Neurolmage 2015, 111:312-320.

51. Jung RE, Wertz CJ, Meadows CA, Ryman SG, Vakhtin AA, Flores RA: Quantity yields quality when it comes to creativity: a brain and behavioral test of the equal-odds rule. Front Psycho 2015, 6.

52. Wirth M, Jann K, Dierks T, Federspiel A, Wiest R, Horn H: Semantic memory involvement in the default mode network: a functional neuroimaging study using independent component analysis. Neurolmage 2011, 54:3057-3066.
53. Humphreys GF, Hoffman P, Visser M, Binney RJ, Lambon Ralph MA: Establishing task- and modality-dependent dissociations between the semantic and default mode networks. Proc Natl Acad Sci U S A 2015, 112:7857-7862.

54. Zabelina DL, Andrews-Hanna JR: Dynamic network interactions supporting internally-oriented cognition. Curr Opin Neurobiol 2016, 40:86-93.

55. Takeuchi H, Taki Y, Nouchi R, Yokoyama R, Kotozaki Y,

- Nakagawa S, Sekiguchi A, lizuka K, Yamamoto Y, Hanawa S et al. Regional homogeneity, resting-state functional connectivity and amplitude of low frequency fluctuation associated with creativity measured by divergent thinking in a sex-specific manner. Neurolmage 2017, 152:258-269.

This fMRI study explored the links between resting state functional connectivity and divergent thinking according to gender. The results showed that the functional connectivity patterns between several networks or regions associated with divergent thinking vary according to sex.

56. Bertossi E, Ciaramelli E: Ventromedial prefrontal damage reduces mind-wandering and biases its temporal focus. Soc Cogn Affect Neurosci 2016, 11:1783-1791.

57. Brunyé TT, Moran JM, Cantelon J, Holmes A, Eddy MD, Mahoney CR, Taylor HA: Increasing breadth of semantic associations with left frontopolar direct current brain stimulation: a role for individual differences. NeuroReport 2015, 26:296-301

58. Green AE, Spiegel KA, Giangrande EJ, Weinberger AB Gallagher NM, Turkeltaub PE: Thinking cap plus thinking zap: tDCS of frontopolar cortex improves creative analogical reasoning and facilitates conscious augmentation of state creativity in verb generation. Cereb Cortex 2016, 27:2628-2639

59. Bertossi E, Peccenini L, Solmi A, Avenanti A, Ciaramelli E: Transcranial direct current stimulation of the medial prefrontal cortex dampens mind-wandering in men. Sci Rep 2017, 7:16962.

60. de Souza LC, GuimarÃ£es HC, Teixeira AL, Caramelli P, Levy R, Dubois B, Volle E: Frontal lobe neurology and the creative mind. Front Psychol 2014, 5.

61. Volle E, De Souza LC: Neurologie et créativité. Esthétique et complexité - II - Neurosciences, évolution, épistémologie, philosophie 2015:373-403.

62. Chrysikou EG, Hamilton RH, Coslett HB, Datta A, Bikson M, Thompson-Schill SL: Noninvasive transcranial direct current stimulation over the left prefrontal cortex facilitates cognitive flexibility in tool use. Cogn Neurosci 2013, 4:81-89.

63. Luft CDB, Zioga I, Banissy MJ, Bhattacharya J: Relaxing learned - constraints through cathodal tDCS on the left dorsolateral prefrontal cortex. Sci Rep 2017, 7:2916.

This study showed that inhibitory stimulation of the left lateral prefronta cortex using tDCS led to better performance in insight problem solving and that it could be explained by a relaxation of previously learned constraints implicitly imposed by the context.

64. Kleinmintz OM, Abecasis D, Tauber A, Geva A, Chistyakov AV,

- Kreinin I, Klein E, Shamay-Tsoory SG: Participation of the left inferior frontal gyrus in human originality. Brain Struct Funct 2018, 223:329-341.

This combined fMRI and TMS study showed that inhibiting activity in the left inferior frontal gyrus can facilitate the generation and evaluation of original ideas.

65. Metuki N, Sela T, Lavidor M: Enhancing cognitive control components of insight problems solving by anodal tDCS of the left dorsolateral prefrontal cortex. Brain Stimul 2012, 5:110-115.

66. Colombo B, Bartesaghi N, Simonelli L, Antonietti A: The combined effects of neurostimulation and priming on creative thinking. A preliminary tDCS study on dorsolateral prefrontal cortex. Front Hum Neurosci 2015, 9

67. Weinberger $A B$, Green AE, Chrysikou EG: Using transcranial direct current stimulation to enhance creative cognition: interactions between task, polarity, and stimulation site. Front Hum Neurosci 2017, 11. 
68. Lucchiari C, Sala PM, Vanutelli ME: Promoting creativity through transcranial direct current stimulation (tDCS). A critical review. Front Behav Neurosci 2018, 12:167.

69. Foulon C, Cerliani L, Kinkingnéhun S, Levy R, Rosso C,

- Urbanski M, Volle E, Thiebaut de Schotten M: Advanced lesion symptom mapping analyses and implementation as BCBtoolkit. GigaScience 2018, 7.

The authors implemented several methods in a freely available software to assess lesion-deficit mapping while considering the functional and structural remote effects of a brain damage.

70. Bendetowicz D, Urbanski M, Aichelburg C, Levy R, Volle E: Brain morphometry predicts individual creative potential and the ability to combine remote ideas. Cortex 2017, 86:216-229.

71. Burgess P, Alderman N, Volle E, Benoit R, Gilbert S: Mesulam's frontal lobe mystery re-examined. Restor Neurol Neurosci 2009 , 27:493-506.

72. Green AE, Kraemer DJM, Fugelsang JA, Gray JR, Dunbar KN: Neural correlates of creativity in analogical reasoning. J Exp Psychol Learn Mem Cogn 2012, 38:264-272.

73. Jones LL, Estes Z: Convergent and divergent thinking in verbal analogy. Think Reason 2015, 21:473-500.

74. Mansouri FA, Koechlin E, Rosa MGP, Buckley MJ: Managing competing goals - a key role for the frontopolar cortex. Nat Rev Neurosci 2017, 18(11):645-657.

75. Urbanski M, Bréchemier M-L, Garcin B, Bendetowicz D, Thiebaut

- de Schotten M, Foulon C, Rosso C, Clarençon F, Dupont S, Pradat-Diehl $P$ et al:: Reasoning by analogy requires the left frontal pole: lesion-deficit mapping and clinical implications. Brain J Neurol 2016, 139:1783-1799.

This lesion study demonstrates that the left rostro-lateral prefrontal region is a critical node in the network sub serving analogical reasoning. The authors suggest that the use of analogy tasks in clinical practice could improve the assessment of abstraction and reasoning abilities in patients with frontal lesions.

76. Beaty RE, Benedek M, Wilkins RW, Jauk E, Fink A, Silvia PJ, Hodges DA, Koschutnig K, Neubauer AC: Creativity and the default network: a functional connectivity analysis of the creative brain at rest. Neuropsychologia 2014, 64:92-98.

77. Vartanian O, Beatty EL, Smith I, Blackler K, Lam Q, Forbes S: One-

- way traffic: the inferior frontal gyrus controls brain activation in the middle temporal gyrus and inferior parietal lobule during divergent thinking. Neuropsychologia 2018, 118(Pt. A):68-78 http://dx.doi.org/10.1016/j.neuropsychologia.2018.02.024.

This fMRI study used an effective connectivity method and showed that the lateral prefrontal cortex PFC exerts a unidirectional control over the middle temporal gyrus and the inferior parietal lobule during divergent thinking.

78. Mayseless N, Shamay-Tsoory SG: Enhancing verbal creativity: modulating creativity by altering the balance between right and left inferior frontal gyrus with tDCS. Neuroscience 2015 291:167-176.

79. Ivancovsky T, Kurman J, Morio H, Shamay-Tsoory S: Transcranial

- direct current stimulation (tDCS) targeting the left inferio frontal gyrus: effects on creativity across cultures. Soc
Neurosci 2018, 16:1-9 http://dx.doi.org/10.1080/

17470919.2018.1464505.

The authors investigated the role of the inferior frontal gyrus in divergent thinking by using tDCS in two different cultural populations. The results showed that stimulating the left inferior frontal gyrus decreased divergent thinking performance, suggesting that this region may have an inhibitory role in creativity, and highlighted differences across the two cultures.

80. Azuar C, Reyes P, Slachevsky A, Volle E, Kinkingnehun S, Kouneiher F, Bravo E, Dubois B, Koechlin E, Levy R: Testing the model of caudo-rostral organization of cognitive control in the human with frontal lesions. Neurolmage 2014, 84:1053-1060.

81. Badre D, Wagner AD: Semantic retrieval, mnemonic control, and prefrontal cortex. Behav Cogn Neurosci Rev 2002, 1:206218.

82. Kan IP, Thompson-Schill SL: Selection from perceptual and conceptual representations. Cogn Affect Behav Neurosci 2004, 4:466-482.

83. Lambon Ralph MA, Jefferies E, Patterson K, Rogers TT: The neural and computational bases of semantic cognition. Nat Rev Neurosci 2016, 18:42.

84. Thompson-Schill SL, Swick D, Farah MJ, D’Esposito M, Kan IP, Knight RT: Verb generation in patients with focal frontal lesions: a neuropsychological test of neuroimaging findings. Proc Natl Acad Sci U S A 1998, 95:15855-15860.

85. Volle E, Costello A de L, Coates LM, McGuire C, Towgood K, Gilbert S, Kinkingnehun S, McNeil JE, Greenwood R, Papps B et al: : Dissociation between verbal response initiation and suppression after prefrontal lesions. Cereb Cortex 2012, 22:2428-2440.

86. Aron AR, Robbins TW, Poldrack RA: Inhibition and the right inferior frontal cortex: one decade on. Trends Cogn Sci 2014 , 18:177-185.

87. Robinson GA, Cipolotti L, Walker DG, Biggs V, Bozzali M, Shallice T: Verbal suppression and strategy use: a role for the right lateral prefrontal cortex? Brain 2015, 138:1084-1096.

88. Cerruti C, Schlaug G: Anodal transcranial direct current stimulation of the prefrontal cortex enhances complex verbal associative thought. J Cogn Neurosci 2009, 21:1980-1987.

89. Zmigrod S, Colzato LS, Hommel B: Stimulating creativity: modulation of convergent and divergent thinking by transcranial direct current stimulation (tDCS). Creat Res J 2015, 27:353-360.

90. Thiebaut de Schotten M, Urbanski M, Batrancourt B, Levy R, Dubois B, Cerliani L, Volle E: Rostro-caudal architecture of the frontal lobes in humans. Cereb Cortex 2017, 27:4033-4047.

91. Chen AC, Oathes DJ, Chang C, Bradley T, Zhou Z-W, Williams LM, Glover GH, Deisseroth K, Etkin A: Causal interactions between fronto-parietal central executive and default-mode networks in humans. Proc Natl Acad Sci U S A 2013, 110:19944-19949.

92. Siegel JS, Ramsey LE, Snyder AZ, Metcalf NV, Chacko RV, Weinberger K, Corbetta M: Disruptions of network connectivity predict impairment in multiple behavioral domains after stroke. PNAS 2016, 113:E4367-E4376. 